\title{
BOSQUEJOS DE LA CIENCIA NACIONAL EN LA AMÉRICA LATINA DEL SIGLO XIX
}

\author{
INTRODUCCION
}

Durante largo tiempo la historiografía de la ciencia ha venido silenciando el mundo latinoamericano. $\mathrm{Y}$, desde luego, no se trata de una realidad casual o inopinada, como tampoco exclusiva de aquellos países, pues responde a una concepción de la ciencia y, por tanto, de lo que merece o no alcanzar el estatuto de hecho histórico memorable. Puede decirse que es consecuencia de una mentalidad para la que sólo tiene pasado cuanto pueda asociarse con la historia de los descubrimientos. Y Latinoamérica no daba la talla, era un mundo "ancho y ajeno", integrado por países injustamente relegados al área suburbial de Occidente. Parece ridículo, pero es cierto: sin gestas que recordar, la historiografía sólo se ha esforzado en inventariar un grueso legajo de errores y carencias.

Ahora bien, hace ya casi dos décadas que un grupo de historiadores ha venido impugnando esa visión eurocéntrica y hecho una apuesta intelectual y cultural arriesgada: mostrar, a través de una labor bifronte -publicística y crítica- que América latina tenía un pasado científico específico, susceptible de análisis y reflexión, ya que las prácticas científicas, hubiesen o no contribuido a la historia de los descubrimientos, tuvieron una continuidad y han formado parte de la trama cultural de sociedades con alta densidad histórica y compleja situación geopolítica.

Para hacer ese ejercicio de voluntad, cuya dimensión política no hizo sombra a su perfil académico, hubo que diseñar programas de investigación y fundar algunos nichos institucionales que les dieran cobijo. No fue fácil, pero se hizo. Y aunque el empeño por hablar de la ciencia de "países sin ciencia" tuvo el carácter de travesía del desierto, ya podemos citar varios grupos de estudiosos radicados en diversos lugares de la América latina que han logrado explorar un nuevo territorio historiográfico y una manera de abordar el pasado de las prácticas científicas distinta a la impuesta desde los centros hegemónicos del saber histórico.

En este punto es obligado mencionar a la Sociedad Latinoamericana de Historia de las Ciencias y de la Tecnología, fundada en 1982, así como a la revista Quipu, su órgano de expresión desde 1984. Ambas instituciones han proporcionado un ámbito académico de reflexión y vertebrado un diálogo internacional, dentro y fuera de la 
región, que ha dado a las discusiones un carácter colectivo y propiciado la aparición de las primeras visiones panorámicas que se han hecho sin ninguna vocación reivindicativa ni apologética. Aún a riesgo de excitar los celos de otros esfuerzos también destacables, creemos que es obligado destacar la aparición de dos obras que han intentado un balance equilibrado. La primera es la Historia social de las ciencias en América latina (México, Editorial Porrúa, 1996), coordinada por Juan José Saldaña e integrada por catorce capítulos que resumen la experiencia acumulada en la última década. El segundo libro, también colectivo, fue editado por Marcos Cueto en 1996, con el título Salud, cultura y sociedad en América latina: nuevas perspectivas históricas (Lima, Ed. IEP). Los nueve autores que participan abordan el tema de la enfermedad como un problema médico y como un reto social.

La mayor parte de la producción historiográfica generada por los nuevos profesionales de la historia de la ciencia en América latina ha estado orientada en torno a varios debates, entre los que ha tenido un carácter estratégico y medular el relativo a las circunstancias que explican el proceso de expansión de la ciencia occidental, así como el de los mecanismos que favorecen la apropiación local de ciertas prácticas y valores científicos. La transmisión de la ciencia no tiene nada de natural, ni tampoco es un proceso homogéneo, unidireccional o inevitable. Este es un punto de convergencia entre los distintos autores, incluidos los que estudian otras áreas geográficas, como la India, Australia, el sudeste asiático o el norte de Africa. Parece haber un consenso sobre el carácter singular que dicho proceso tiene en cada lugar y la necesidad de abordar la ciencia como una cultura localmente arraigada. Dicha especificidad de las periferias de la ciencia-mundo, por usar los conceptos que introdujo Xavier Polanco, guarda relación con el hecho de que los científicos, sin dejar de actuar como agentes de políticas estatales, han estado sometidos a poderosas presiones de carácter nacionalista. $\mathrm{Y}$ así la ciencia era a un tiempo la panacea para todos los males de la patria y paradójicamente el arma principal de la penetración colonial o imperialista. En ambos casos la incorporación de la ciencia moderna era un reto al que se le querían poner condiciones, pues no todo lo que robustecía las estructuras estatales, era igualmente favorable para la formación de la nacionalidad. Más aún; dado que el desarrollo de las actividades científicas dependía en gran medida del apoyo del estado, hubo una tendencia a que los colectivos profesionales se comprometiesen con las exigencias locales. En contrapartida, los científicos tuvieron que desplegar sutiles estrategias de legitimación internacional de su actividad para alcanzar ciertas cotas de autonomía y así protegerse de los vaivenes de la política. Y, con frecuencia, antes que integrarse en el aparato tecnocrático del estado, buscaron el apoyo social necesario adhiriéndose a movimientos nacionalistas que les movieron a ensayar con categorías conceptuales o con objetos de estudio frecuentemente heterodoxos. No siempre tuvieron éxito en la aventura, pero hay registrados varios casos, estudiados por Cueto, Stepan, Lemoine o Glick, por solo citar algunos ejemplos memorables, en los que 


\section{INTRODUCCIÓN}

"el descubrimiento" tuvo este origen cultural e ideológico. No es pues inmediata la relación entre ciencia, estado y nación, como tampoco homogénea la respuesta que se dio en cada lugar a los retos de la modernización cultural.

Otra importante área de intereses se ha nucleado en torno al problema de la transmisión transcultural de la ciencia, es decir al papel de la ciencia entendida como un elemento de la identidad cultural latinoamericana y distinto del que desempeña en el mundo europeo o noratlántico. En este campo la atención de los investigadores se ha dirigido al estudio de cómo se adaptan los objetos y prácticas científicas en distintos contextos locales, analizando los procesos de recepción de ideas, valores o formas institucionales procedentes del exterior, así como los mecanismos de adaptación (o de relocalización) en un contexto diferenciado. Porque contra lo que ha venido siendo un hábito inveterado, el polo receptor de todo proceso de transmisión no es un elemento pasivo de la cadena, sino que se manifiesta capaz de imponer condiciones, ya sea al elegir los objetos aceptables, ya sea jerarquizándolos de otra manera a como lo estaban en el lugar de origen. En todo caso, siempre hay una interacción fecunda entre lo nuevo y lo tradicional, así como una aplicación del híbrido resultante a objetivos distintos, una operación que transforma la experiencia y el sentido de las ideas o prácticas en rotación. Y claro está, en esa domesticación de los saberes la cultura local desempeña un papel decisivo, y dota a la ciencia autóctona de perfiles singulares. Los historiadores latinoamericanos, como también los de otras regiones periféricas, han insistido en la importancia del nacionalismo no sólo como motor de la modernización científica, sino también como principal estímulo a la innovación conceptual e institucional. La complejidad de ese fenómeno de transmisión transcultural de la ciencia, que ocurre en paralelo al de transculturación de otras manifestaciones culturales como la literatura o el arte, se acentúa por el hecho de que en su gestación también son importantes las acciones de científicos latinoamericanos en los centros europeos o en otros centros periféricos. Y así, la circulación de prácticas y saberes no es sólo pluridireccional, sino también multicéntrica.

Este movimiento historiográfico de reflexión y análisis sobre las modalidades en las que se han efectuado la producción y reproducción de conocimientos científicos en la región latinoamericana ha permitido renovar el andamiaje teórico sobre el que se construyeron las imágenes del pasado científico de América latina. Mientras dominó la teoría de la dependencia, allá por los años 60 y 70, se insistió en el carácter marginal, subordinado y precario de la ciencia latinoamericana en el conjunto del sistema de la ciencia-mundo. Y si bien esas imágenes no son por entero caprichosas o impertinentes, también es cierto que gracias al trabajo historiográfico efectuado en las dos últimas décadas se ha podido comprobar que la realidad colonial o imperialista no ha asfixiado toda posibilidad de desarrollo científico endógeno. Y si así hubiera sido, como muchos todavía sostienen, entonces habría que plantearse hasta qué punto es estrecha la relación entre ciencia y poder; es decir, si cabe buena ciencia sin 


\section{ANTONIO LAFUENTE Y LEONCIO LÓPEZ-OCÓN}

mucho poder o si dicho poder no es sino la manera que tiene de hacerse notoria la mucha ciencia. Nosotros no negaremos la obviedad de tales relaciones, pero sí queremos discutir el reduccionismo que habitaba en el interior de la teoría de la dependencia, comparable, aunque de signo contrario, al que sostuvieron los partidarios de la teoría de la modernización.

En fin, esta introducción no es el lugar para perdernos por tales derroteros. Aquí nos basta con insistir en la pertinencia de los estudios latinoamericanos de la ciencia, así como en su carácter innovador. Y no es que los problemas ya estén resueltos, o que la plataforma conceptual sobre la que se está construyendo esté acabada o sea perfecta, sino que, por el momento, se han problematizado las viejas soluciones y abierto distintas maneras de abordar las cuestiones. No es poco si se tiene en cuenta la dificultad que se tiene en los suburbios pobres de Occidente, como llamó Alain Touraine a Latinoamérica, para hacerse escuchar.

Recientemente la Union International of History of Science designó a la ciudad de México como sede para su próximo Congreso en el año 2001. Será el primer Congreso del próximo milenio y también el primero que se celebra en Latinoamérica y en un país de los llamados periféricos. Se trata de una significativa novedad que viene a refrendar los esfuerzos antes comentados. La historia de la ciencia en los países ibéricos e iberoamericanos ha conocido un momento dulce que ya no puede seguir siendo ignorado. La presentación de este número monográfico de la revista Asclepio, iniciativa que fue aprobada por su Comité de Redacción en 1996, es otra manifestación de la creciente visibilidad y reciente pujanza de la comunidad de historiadores latinoamericanos de la ciencia.

Para esta ocasión se ha elegido un tema que había venido siendo descuidado: el siglo XIX, etapa crucial en la formación de los nuevos estados americanos, pero al estar situado entre dos momentos brillantes, el final de la Ilustración y las primeras décadas de esta centuria, fue eclipsado. Junto a la consolidación del actual mapa político latinoamericano, se produjo la transición desde la fase de ciencia colonial, bajo el dominio de los imperios español y portugués, a la de ciencia nacional. Es decir la actividad científica pasó de estar dominada casi exclusivamente por el influjo de instituciones europeas a ser generada desde el interior de esas mismas sociedades respondiendo a sus propias exigencias locales. Quienes se han interesado por la emergencia y consolidación de esta ciencia nacional subrayan entonces el papel que desempeña la "ecología" en la elaboración de los conocimientos científicos y destacan la riqueza de relaciones que la ciencia y los científicos son capaces de establecer con su medio local. El siglo XIX, al igual que otros períodos del pasado latinoamericano, ha estado sometido a la tiranía de un interminable rosario de prejuicios. Muchos tópicos y lugares comunes han colonizado su historia. Demasiados e impenitentes, según García Márquez, quien no dudó en utilizar su discurso de recepción del Premio Nobel para afirmar que cuanto más se hablaba de Latinoamérica, más extraviada se 


\section{INTRODUCCIÓN}

encontraba la identidad de sus pobladores. Durante largo tiempo se ha considerado que el Ochocientos, identificado con la presencia de fieros e ignorantes caudillos, vio consolidarse todos los males de las sociedades latinoamericanas: atraso científico y técnico, dependencia del exterior, apropiación del estado por los juristas, formación de unas élites con cultura humanística obsoleta e indiferente a la ciencia. Y sin embargo, como ha empezado a mostrar la reciente investigación histórica y pondrán de manifiesto las páginas siguientes, la realidad fue más compleja y atractiva.

Si bien es cierto que el nuevo orden republicano fue difícil de construir en sociedades mal vertebradas, multirraciales y mayoritariamente analfabetas, además de muy diseminadas en inmensos espacios geográficos, también se puede afirmar que el interés por los saberes científico-técnicos y su aplicación estuvo siempre presente en la mayoría de las políticas impulsadas en esa región. La "era de la ciencia", como nombró Knight al siglo XIX , también se hizo presente en América latina. Y en efecto la ciencia parece haber tenido un papel más importante del que se había supuesto hasta ahora en la construcción de los nuevos Estados nacionales latinoamericanos. Y así los gobernantes recurrieron a naturalistas para impulsar vastos programas de investigación destinados al conocimiento y evaluación de los recursos naturales y humanos de las nuevas entidades políticas, $o$ adoptaron medidas de diferente calibre, recurriendo a los médicos o a los ingenieros, para poner en práctica planes de salud pública o de salubridad urbana con los que domesticar el entorno.

Pero, en fin, para conocer más en detalle esa imbricación entre ciencia, poder, cultura y sociedad mientras avanzaba el proceso de construcción y consolidación de los Estados nacionales latinoamericanos durante el siglo XIX, invitamos al lector a adentrarse en este monográfico, compuesto de nueve aportaciones que cubren aspectos diferentes y complementarios del desenvolvimiento de la ciencia. Dada la importancia que tuvo el nuevo conglomerado de problemas alrededor de la noción de Estado-nación no ha de extrañar que siete de los artículos tengan como objeto el análisis de la realidad nacional (¡y nacionalista!), en Colombia, México, Brasil y Argentina. Así pues faltan aproximaciones a otras partes de la región y, sin embargo, tenemos la impresión de que la panoplia de casos presentada es suficiente. El volumen no tiene un afán exhaustivo, sino que más bien es sostenido por la ilusión de presentar algunos casos relevantes que ayuden a elaborar nuevas o más generales hipótesis y, desde luego, a mostrar el estado actual de ciertos problemas y a detectar lagunas y zonas de sombra cara a investigaciones futuras. De ahí que se presenten dos tipos de propuestas analíticas. Por un lado, se dan a conocer trabajos con una amplia perspectiva historiográfica, como son los de Olga Restrepo, Luz Fernanda Azuela / Rafael Guevara Fefer y Silvia Figueiroa, que se han esforzado en presentar un balance del punto en el que se encuentran los estudios sobre el desenvolvimiento científico ochocentista de Colombia, México y Brasil, respectivamente. En ellos se matiza el papel del Estado como agente promotor de ciencia, y se subraya cómo la 


\title{
ANTONIO LAFUENTE Y LEONCIO LÓPEZ-OCÓN
}

institucionalización de dichas actividades es resultado de la interacción entre influencias foráneas y condiciones locales. Y subrayamos la segunda parte del binomio, porque la historiografía difusionista no ha querido otorgar importancia más que al factor exterior. Las cuatro aportaciones correspondientes a Diana Obregón, Ana María Carrillo, Flavio Coelho Edler y Ricardo Omar González Leandri, responden mejor al tipo de estudios de casos, pues todas abordan desde enfoques diferentes y complementarios el análisis del proceso de construcción de una medicina nacional en Colombia, México, Brasil y Argentina, respectivamente. Esta aparente sobrerrepresentación de la historiografía de la medicina no ha de extrañarnos dado que, como en todas las comunidades científicas emergentes, los médicos son el contingente profesional más numeroso y el que primero adquiere una considerable autonomía institucional. El volumen se abre y se cierra con dos contribuciones -de Jorge Cañizares y de Leoncio López-Ocón- que pretenden ofrecer sendas visiones panorámicas del desarrollo científico latinoamericano del siglo XIX, con un sesgo comparativo.

Tal vez nuestros los lectores echen en falta la concurrencia de algún tema, disciplina o país. Sin duda tienen razón, máxime cuando nos referimos a un área que Germán Arciniegas calificó como "el continente de siete colores", pero admitamos que el buen producto es enemigo de la obra perfecta. Y con esa convicción nos hemos animado a ofrecer un texto que esperamos que contribuya a airear la historiografía y a deshacer algún tópico.

\author{
ANTONIO LAFUENTE \\ LEONCIO LÓPEZ-OCÓN \\ Departamento de Historia de la Ciencia. \\ Centro de Estudios Históricos, CSIC. \\ Madrid (España)
}

